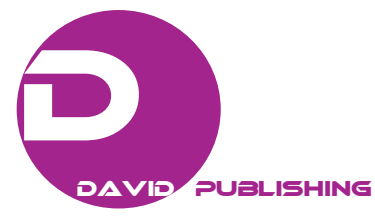

\title{
Heat Transfer Performance of a Multi-heat Pipe Using Graphene Oxide/Water Nanofluid
}

\author{
Mohamed Salem ${ }^{1,3}$, Tarek A. Meakhail ${ }^{1}$, Magdy A. Bassily ${ }^{2}$ and Shuichi Torii ${ }^{3}$ \\ 1. Department of Mechanical Engineering, Faculty of Energy Engineering, Aswan University, Aswan 81528, Egypt \\ 2. Department of Mechanical Engineering, Faculty of Engineering, Minia University, Minia 61519, Egypt \\ 3. Graduate School of Science and Technology, Kumamoto University, Kumamoto 860-8555, Japan
}

Received: October 26, 2016 / Accepted: November 07, 2016 / Published: February 28, 2017.

\begin{abstract}
A multi-heat pipe is a device for heat transmission. It is composed of a heating section, a cooling section and an adiabatic section. The heating and cooling sections are the same and both are connected by four circular parallel tubes. This experimental study is performed to investigate heat transfer performance of a multi-heat pipe in the vertical orientation using pure water and GO (graphene oxide)/water nanofluid. GO/water nanofluids were synthesized by the modified Hummers method with $0.05 \%, 0.1 \%, 0.15 \%$, and $0.2 \%$ volume concentrations. The thermal performance has been investigated with varying heat flux in the range of $10-30 \mathrm{~W}$ and $100 \%$ fill charge ratio. Wall temperature, thermal resistance, and heat transfer coefficient of the heat pipe are measured and compared with those for the heat pipe using pure water. The experimental results show that the evaporator wall temperature with GO nanofluid is lower than that of the base fluid. Also, the heat pipe that charged with nanofluids showed lower thermal resistance compared with pure water. Heat transfer enhancement is caused by suspended nanoparticles and is pronounced with the increase in particle volume fraction.
\end{abstract}

Key words: Nanofluid, graphene oxide, multi-heat pipe, thermal performance.

\section{Introduction}

With an ever-increasing thermal load due to smaller features of microelectronic devices and more power output, cooling for maintaining desirable performance and durability of such devices is one of the most important technical issues in many high-tech industries. Scientists have tried to find new techniques to solve the problems of increasing temperatures of electronic devices which limited their performances. Heat pipes are one of the most effective heat transfer devices that can transport thermal energy from one point (evaporator) to another (condenser) by utilizing the phase change of working fluid. A heat pipe is composed of three parts (evaporator, adiabatic section, and condenser) that are placed vertically one on top of

Corresponding author: Mohamed Salem, Ph.D. student, research field: heat transfer enhancement of graphene oxide nanofluid. the other. The evaporator section is filled with certain amount of working fluid which vaporizes, when the heat input is supplied and the vapour passes through the adiabatic section and gets condensed in the condenser section. The condensed liquid falls back to the evaporator through the walls of the heat pipe due the action of gravity.

Kole and Dey [1] studied the effect of copper/water nanofluids on the thermal performance of a screen mesh wick heat pipes under constant heat flux. They found that the heat transfer performance was amplified by suspension of nanoparticles in comparison with that of pure water and the effect became large as the concentration of nanofluid increased. Lazarus et al. [2] investigated experimentally the heat transfer enhancement of a glass thermosyphon using graphene-acetone nanofluid with various volume concentrations varying from $0.05 \%$ to $0.09 \%$. Experimental results showed that the thermal 
resistance of thermosyphon was decreased by $70.3 \%$ with the used of graphene-acetone nanofluid. Azizi et al. [3] analyzed experimentally the effect of graphene/water nanofluid on the thermal performance of a two-phase closed thermosyphon with various weight concentrations ranged from $0.02 \%$ to $1 \%$ at the input power of 30-150 W. The reported results showed that the highest thermal efficiency (90.2\%) was obtained in the concentration of $1 \mathrm{wt} . \%$ and with input power of $120 \mathrm{~W}$. Kim and Bang [4] carried out experiments to observe the effect of GO (graphene oxide)/water nanofluids ( 0.01 and 0.03 vol.\%) on the heat pipe performance and capillary limits. A $25 \%$ reduction of the thermal resistance at the evaporator section was observed. Also, the capillary limit of the heat pipe contains $\mathrm{GO} /$ water nanofluids was higher than water heat pipe. Noie et al. [5] showed heat transfer enhancement by using $\mathrm{Al}_{2} \mathrm{O}_{3}$ /water nanofluid in a two-phase closed thermosyphon with different volume concentrations of nanoparticles (1-3\%). They showed that the efficiency of the two-phase closed thermosyphon increases up to $14.7 \%$ when $\mathrm{Al}_{2} \mathrm{O}_{3} /$ water nanofluid was used instead of pure water. Guo and Nutter [6] experimentally investigated the effect of the axial conduction through the pipe wall on the performance of a thermosyphon using R134a as the working fluid. The experimental data showed that the conduction through the pipe wall caused the wall temperature to decrease along the evaporator section. It also increased the overall heat transfer coefficient, evaporation heat transfer coefficient, and condensation heat transfer coefficient of the thermosyphon. Ghanbarpour et al. [7] performed experimental study to investigate the thermal performance of screen mesh heat pipes using distilled water and $\mathrm{Al}_{2} \mathrm{O}_{3}$ /water nanofluids with mass concentrations of $5 \%$ and $10 \%$ as working fluids. The results revealed that the thermal performance of the heat pipe increased utilizing $5 \mathrm{wt} . \%$ while it was decreased with 10 wt.\% compared with distilled water. Menlik et al. [8] investigated the effect of $\mathrm{MgO} /$ water nanofluid on the thermal performance of a two-phase closed thermosyphon heat pipe at various states of operation. They concluded that the thermal performance of $\mathrm{MgO}$ /water nanofluid was better than that of deionized water, the highest improvement in efficiency was determined as $26 \%$. Goshayeshi et al. [9] studied experimentally the effect of $\mathrm{Fe}_{2} \mathrm{O}_{3}$ /kerosene nanofluid to the copper closed-loop oscillating heat pipe under the magnetic field for inclination angles ranged from $0^{\circ}$ to $90^{\circ}$, under different heat inputs $(10-90 \mathrm{~W})$. They confirmed that the performance was improved, but performance was deteriorated at the tilt angles between $75^{\circ}$ and $90^{\circ}$. Noie [10] investigated the effect of input heat transfer rates (100-900 W), the working fluid filling ratios (30-90\%) and aspect ratios (evaporator lengths) on the heat transfer characteristics of a vertical two-phase closed thermosyphon. Karthikeyan et al. [11] carried out experiments to observe the effect of nanofluids (copper and silver colloidal nanofluids) on the thermal performance of closed loop pulsating heat pipe. The thermal performance of the device investigated with varying heat power in the range of $50-240 \mathrm{~W}$ in the vertical orientation. Experiment results showed that the wall temperature was decreased with the used of nanofluids compared to that of pure water. Wannapakhe et al. [12] studied the effect of aspect ratio, inclination angles and concentrations of silver nanofluid on heat rate of closed-loop oscillating heat pipe with check valves. In their study they emphasized that the suspension of nanoparticles increased the heat capacity of the fluid, and the best inclination for using heat pipe was $90^{\circ}$ from the horizontal axis. Yulong et al. [13] experimentally investigated the effect of particle size of $\mathrm{Al}_{2} \mathrm{O}_{3}$ on heat transfer performance in an oscillating heat pipe. Four size particles with average diameter of $50 \mathrm{~nm}, 80 \mathrm{~nm}, 2.2 \mu \mathrm{m}$, and $20 \mu \mathrm{m}$ were studied. They found that all particles size can improve the startup performance even with $20 \mu \mathrm{m}$. Also, shrinkage of particle size enhanced the heat pipe thermal performance. Salem et al. [14] measured thermal conductivity of graphene oxide/water nanofluid with 
different volume concentration ranged from $0.05 \%$ to $0.2 \%$ using transient hot wire method (KD2 thermal property meter). They showed that the thermal conductivity was enhanced with reference to pure water. Also, it was increased by increasing nanoparticles concentration.

In this research, the thermal performance of a multi-heat pipe was investigated experimentally under different constant heat fluxes (10-30 W) and 100\% fill charge ratio. Pure water and various volume concentrations of $\mathrm{GO} /$ water nanofluid $(0.05-0.2 \%)$ were employed as working fluid.

\section{Materials and Methods}

\subsection{Materials}

GO was synthesized from natural graphite powder by a modified Hummers method [15]. Graphite fine powders $(45 \mu \mathrm{m})$ was purchased from Wako pure chemical industries (Japan), concentrated sulfuric acids $\left(\mathrm{H}_{2} \mathrm{SO}_{4}\right)$, sodium nitrate $\left(\mathrm{NaNO}_{3}\right)$, potassium permanganate $\left(\mathrm{KMnO}_{4}\right)$, hydrogen peroxide $(30 \%$ $\mathrm{H}_{2} \mathrm{O}_{2}$ ), hydrochloric acid (5\% HCL) and deionized water were used throughout the experiment. Four volume fractions were prepared for graphene oxide nanofluids $0.05 \%, 0.1 \%, 0.15 \%$ and $0.2 \%$ with different $\mathrm{pH}$ values $6.38,4.95,5.97$ and 5.62 respectively (Fig. 1) .

\subsection{Experimental Method}

A multi-heat pipe was made in laboratory of Kumamoto University-Japan (Fig. 2). It is composed of heating, cooling, and adiabatic section. The external dimensions for heating and cooling sections are $45 \times 45$ $\times 8 \mathrm{~mm}$, and the internal dimensions are $42 \times 42 \times 5$ $\mathrm{mm}$. The adiabatic section is consisted of four parallel circular tubes whose dimension is $\phi 6$ (external diameter $) \times \phi 5$ (inlet diameter) $\times 45 \mathrm{~mm}$ (length) .

A schematic diagram of experimental apparatus is described in Fig. 3. A multi-heat pipe is heated by heater block made from copper containing five heaters (HAKKO, Japan) which connected with transformer

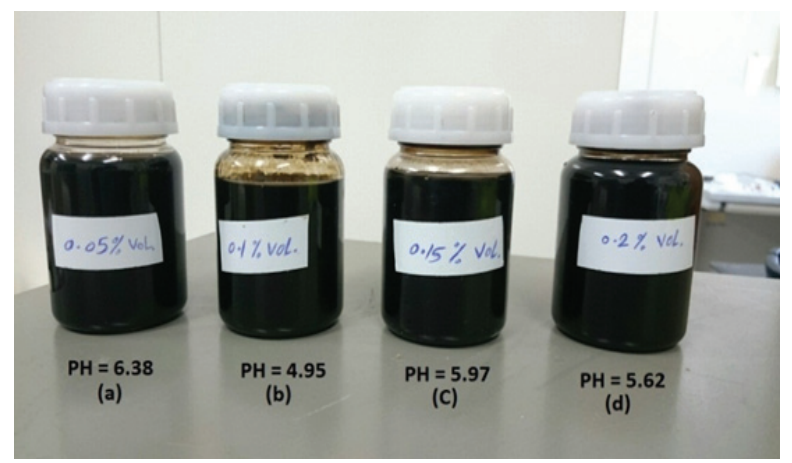

Fig. 1 Graphene oxide nanofluids: (a) 0.05 vol.\%, (b) 0.1 vol. \%, (c) 0.15 vol.\%, and (d) 0.2 vol. \%.

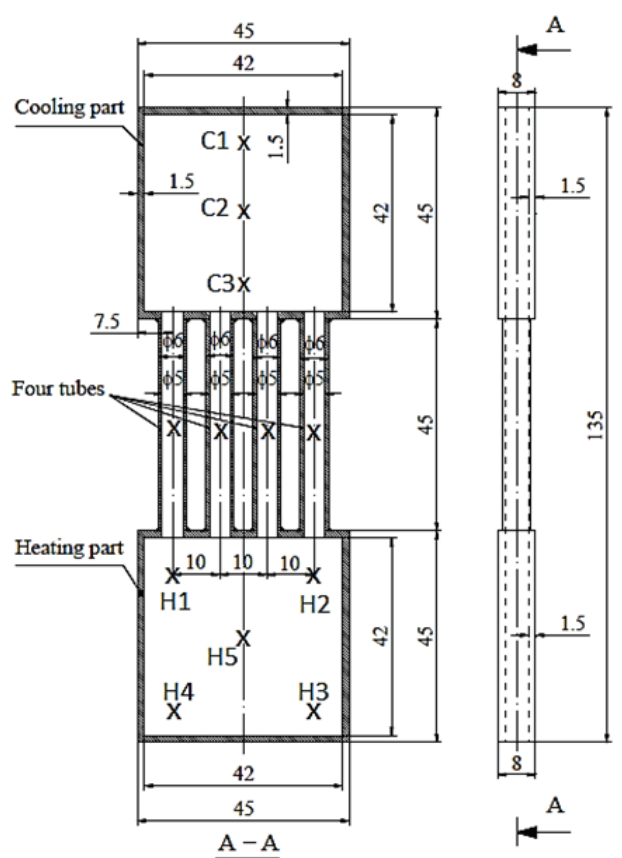

Fig. 2 Thermocouples location (all dimensions are in $\mathbf{~ m m}$ ).

(YAMABISHI, Japan) and its voltage and power are measured by the digital multi-meter (HIOKI, Japan). An adequate amount of working fluid is filled inside of the heat pipe by burette (NALJENE, USA). Vacuum pressure inside the heat pipe is generated by the vacuum pump (ULVAC KIKO, Japan). The cooling section of the heat pipe is cooled by cooling water set at $15{ }^{\circ} \mathrm{C}$ by thermostatic bath (NCC-1100, Japan) with the measurement of flow by flow meter (KOFLOC, Japan). The temperature of heat pipe is measured by twelve K-type thermocouples (Fig. 2), with five of them embedded in the heating section ( $\mathrm{H} 1, \mathrm{H} 2, \mathrm{H} 3, \mathrm{H} 4$, and $\mathrm{H} 5)$, four in the adiabatic section (a1, a2, a3, and a4), and three in the condenser $(\mathrm{C} 1, \mathrm{C} 2$, and $\mathrm{C} 3)$. 


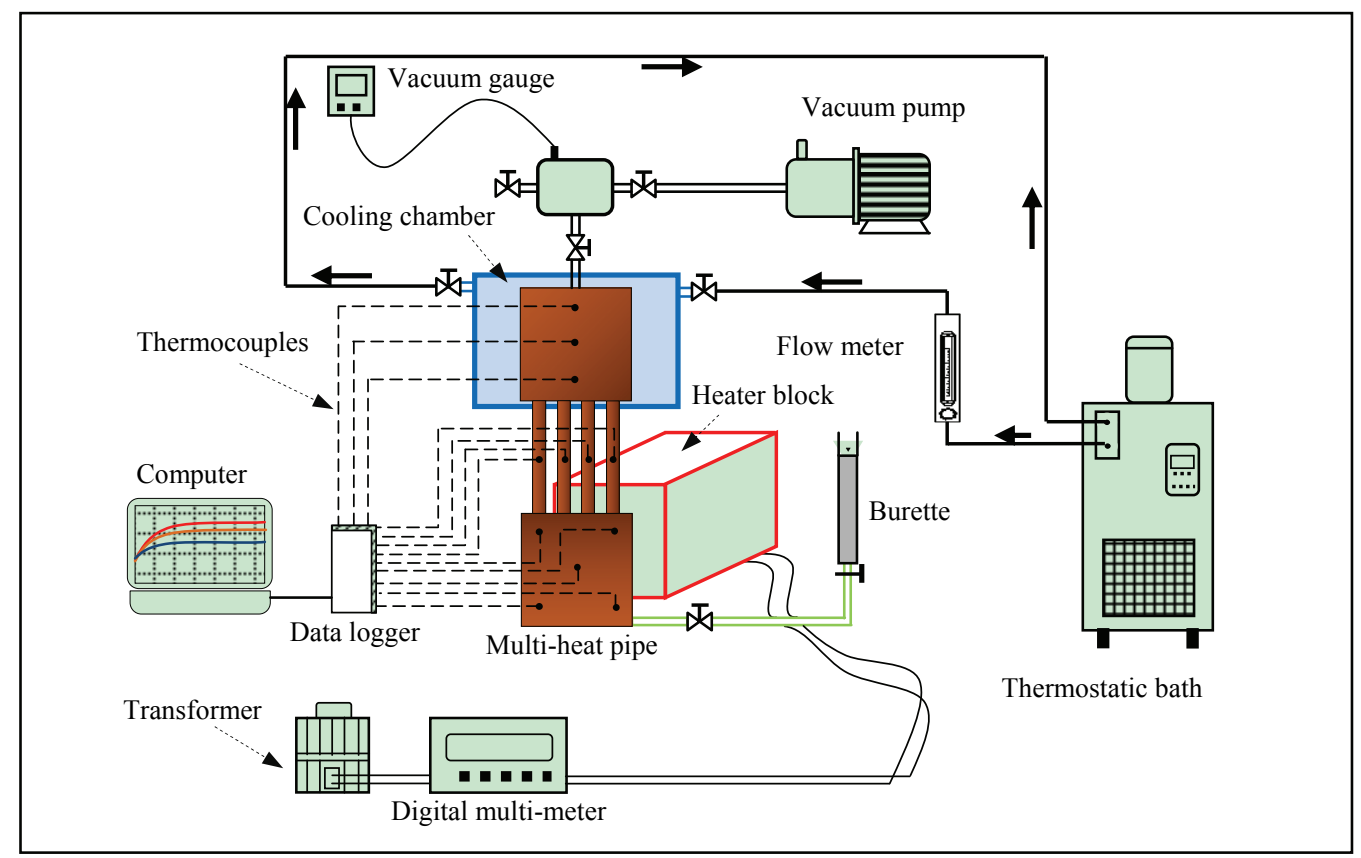

Fig. 3 Schematic diagram of experimental apparatus.

During experiment, the adiabatic section and heating section are insulated with glass fiber to prevent heat loss, the cooling section is inserted to a water tank made by plastic to contain cooling water flowed circularly from the thermostatic bath.

In this experiment, the working fluid was pure water and $\mathrm{GO} /$ water nanofluid with volume concentrations $0.05,0.1,0.15$, and $0.2 \%$. The test section was charged with the working fluid at $100 \%$ fill ratio (volume ratio of the working fluid to internal heating section volume). The pressure inside the test section was set to $9.5 \mathrm{kPa}$ via vacuum pump for all cases. The test section is heated under constant heat fluxes $(10,15,20$, 25 and $30 \mathrm{~W}$ ) and the cooling water supplied to the water tank at a rate of $1.5 \mathrm{~L} / \mathrm{min}$ at $15{ }^{\circ} \mathrm{C}$ inlet temperature.

\section{Results and Discussion}

The effect of employing GO/water nanofluids on the heat pipe thermal performance can be explained by measuring and calculating the variation of temperatures, the thermal resistance, and heat transfer coefficient of the heat pipe and comparing these parameters with those of the heat pipe with pure water.
The readings from the twelve thermocouples were used to calculate the mean temperature of evaporator $\left(T_{H}\right)$, condenser $\left(T_{C}\right)$, and adiabatic section $\left(T_{a}\right)$.

\subsection{Temperature Evolution}

The mean wall temperature evolution of the heating section (evaporator) and cooling section (condenser) of the heat pipe with the fill charge ratio of $100 \%$ and heat flux is increased from $10 \mathrm{~W}$ to $30 \mathrm{~W}$ at $5 \mathrm{~W}$ intervals are shown in Figs. 4 and 5. For all the last figures, it has been observed the initial temperatures of evaporator and condenser section are different for each experiment. This is dependent on the temperature of heater block before contacting with the heating section in each experiment, but this does not affect to the results of the experiment. Moreover, the wall temperature gets steady state after short time $(0 \sim 1,000 \mathrm{~s})$ and this steady state is desirable for electrical or electronic devices that need to be cooled. From Fig. 4, it is clearly seen that a reduction in evaporator's wall temperature is observed for each heat load when the concentration of nanofluid increases. The maximum reduction in evaporator's wall temperature for $10 \mathrm{~W}, 15 \mathrm{~W}, 20 \mathrm{~W}, 25 \mathrm{~W}$ and 30 W is about $8.5^{\circ} \mathrm{C}, 8.6{ }^{\circ} \mathrm{C}, 9.08^{\circ} \mathrm{C}, 8.3^{\circ} \mathrm{C}$ and $9.48{ }^{\circ} \mathrm{C}$, 


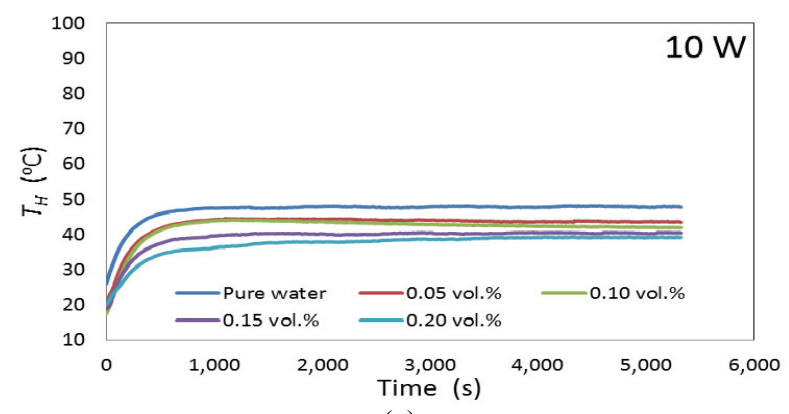

(a)

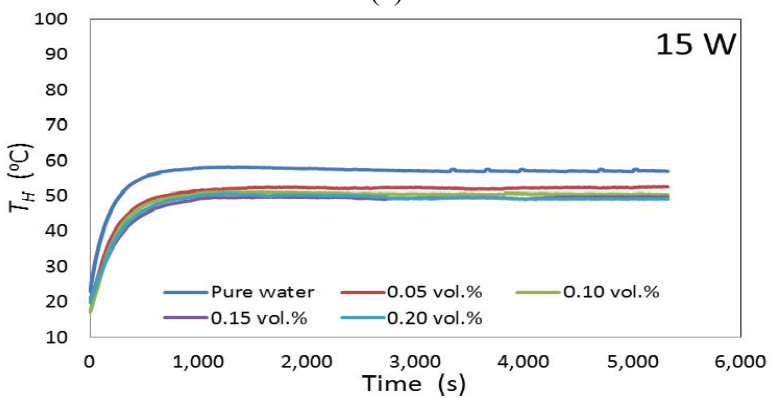

(b)

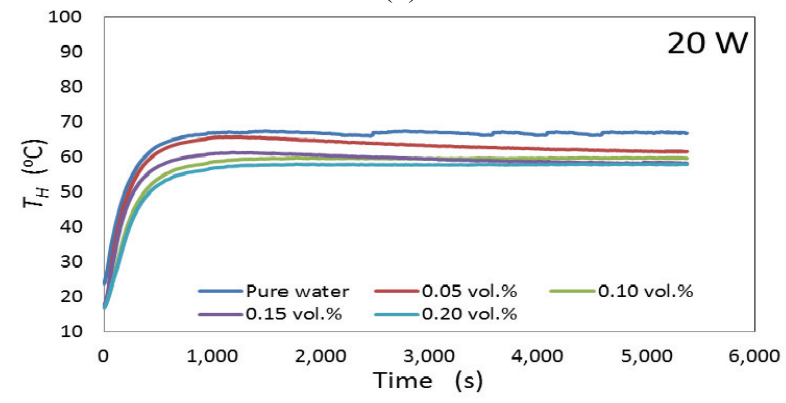

(c)

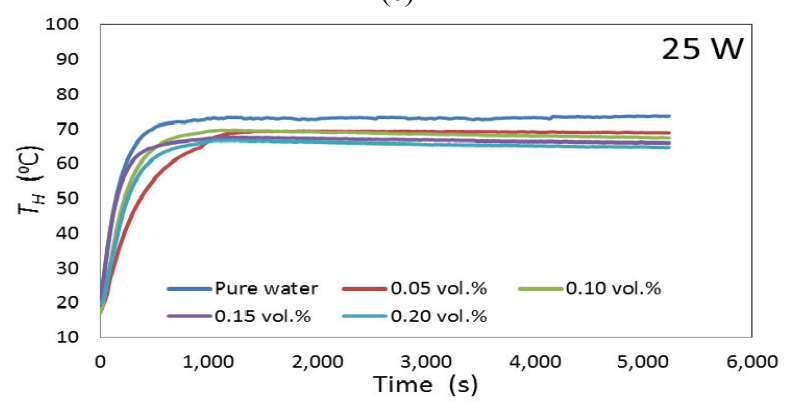

(d)

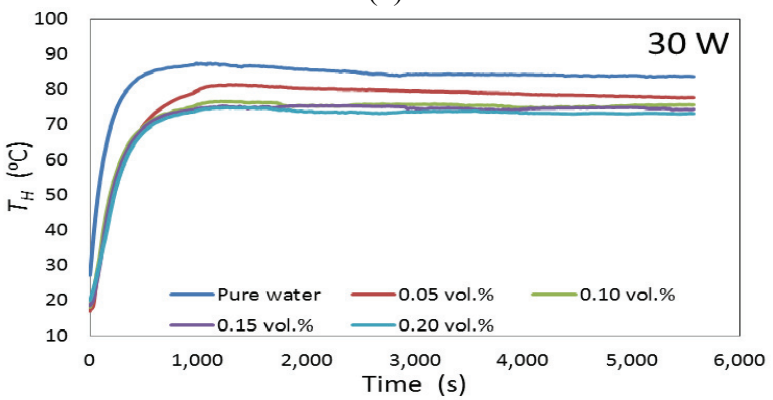

(e)

Fig. 4 Wall temperature evolution of evaporator for different heat powers.

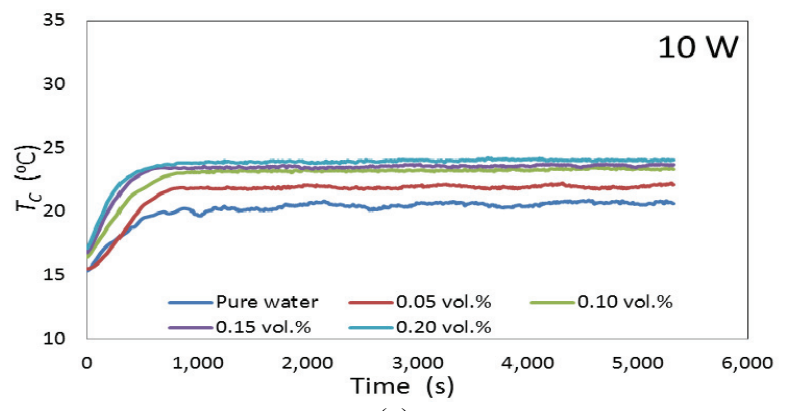

(a)

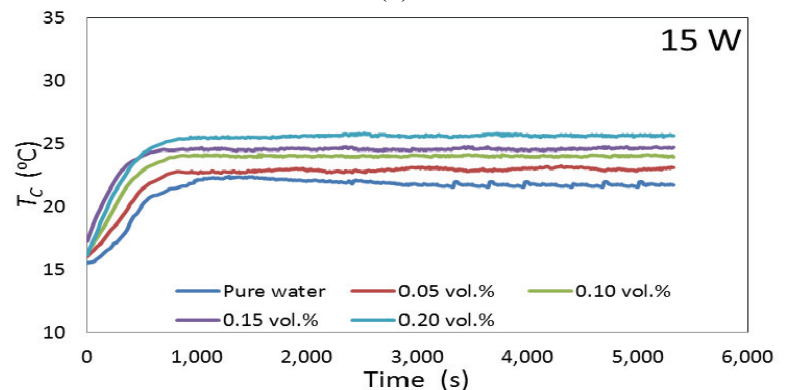

(b)

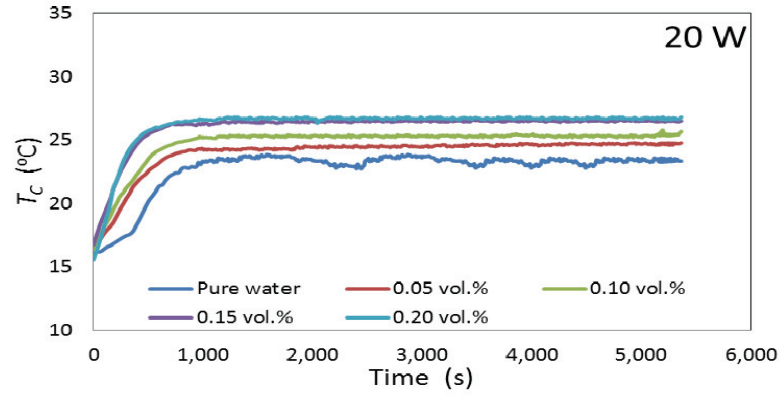

(c)

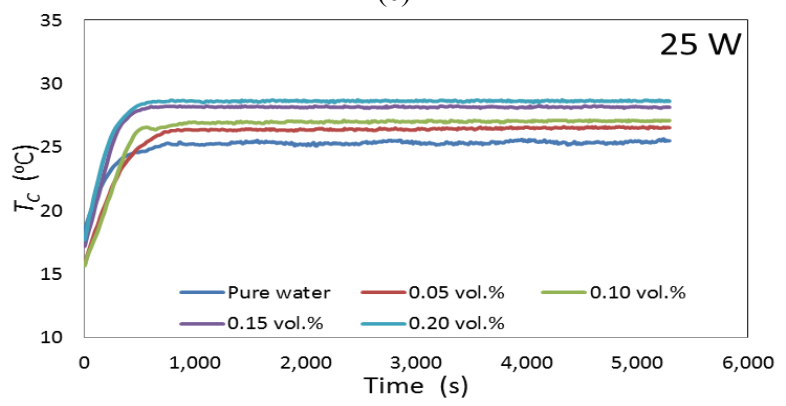

(d)

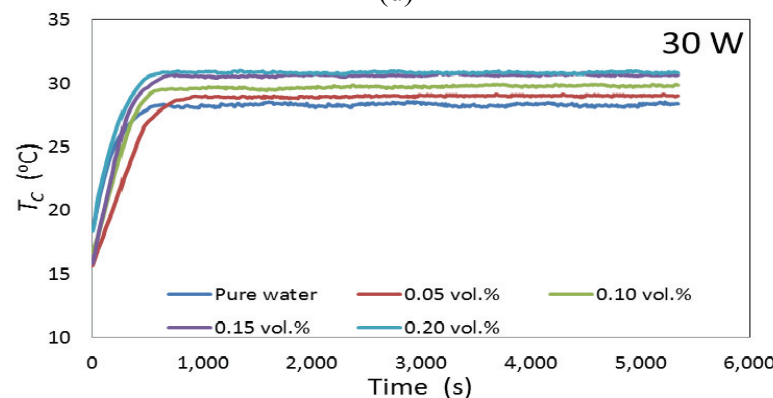

(e)

Fig. 5 Wall temperature evolution of condenser for different heat powers. 
respectively, at the maximum concentration of 0.2 vol.\% when compared with that of pure water. This drop in temperature increases the operating range of heat pipe. It is also observed that the mean temperature of the evaporator increases with the increment of heat input. Maximum evaporator's temperature will be obtained at the highest heat input. From Fig. 5, the mean temperature of the condenser section increased as the heat load increased, because the amount of vapor from the evaporator section reaching to the condenser section increased. Also, the wall temperature increases when the concentration of GO particles increases. The percentage of increase in wall temperature of condenser at $10 \mathrm{~W}$ was $7 \%, 12.52 \%, 14.38 \%$, and $16.57 \%$, respectively, for $0.05 \%, 0.1 \%, 0.15 \%$, and $0.2 \%$ volume concentration.

The vapor temperature $\left(T_{v}\right)$ was calculated as the arithmetic average of the thermocouples $T_{a 1}, T_{a 2}, T_{a 3}$ and $T_{a 4}$ that attached to the surface of the adiabatic section. From Fig. 6, it is observed that the adiabatic wall temperature (vapor temperature) of the heat pipe increases as heat input. For each heat load, the variation of vapor temperature is very small for all concentrations.

\subsection{Thermal Resistance}

The overall thermal resistance of the heat pipe $\left(R_{t h}\right)$ is measured from the average temperature difference between the evaporator and the condenser sections and the input power (Eq. (1)).

$$
\begin{gathered}
R_{t h}=\frac{T_{H}-T_{C}}{Q_{i n}} \\
Q_{i n}=V \bullet I
\end{gathered}
$$

where, $V$ and $I$ are the applied voltage and current, respectively.

Fig. 7 shows the variation in the thermal resistances of multi-heat pipe with different heat load for pure water and $\mathrm{GO} /$ water nanofluids at different volume concentrations. From Fig. 7, it is clear that the thermal

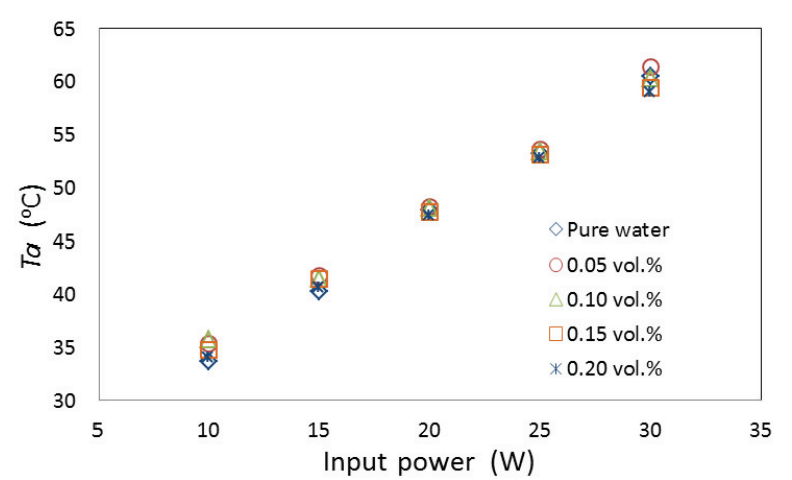

Fig. 6 Adiabatic wall temperature as a function of input power.

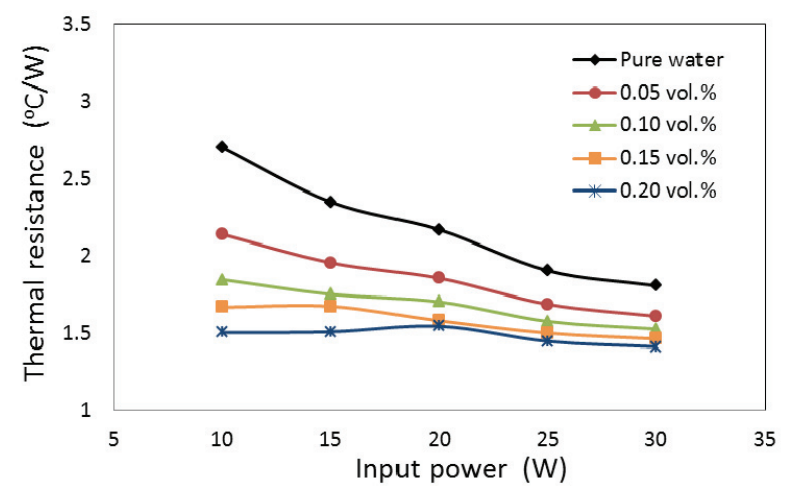

Fig. 7 Thermal resistance as a function of input power.

resistance of multi-heat pipe decreases for pure water and $\mathrm{GO} /$ water nanofluids with increasing the values of the heat input. However, the thermal resistances of the heat pipe using both the pure water and nanofluids are found to be high at lower heat loads for the reason that the vapor condensed quickly when the heat load is increased.

As can be seen, increasing GO nanoparticles as the dispersed phase in water can significantly reduce the thermal resistance of the heat pipe. Also, the minimum thermal resistance occurs with the maximum input power (heat load) and $\mathrm{GO} /$ water nanofluid concentration. The overall thermal resistance at $10 \mathrm{~W}$ reduces by $20.88 \%, 31.74 \%, 38.34 \%$, and $44.45 \%$ for $0.05,0.1,0.15,0.2$ vol. $\%$, respectively, when compared with that of the pure water.

\subsection{Heat Transfer Coefficient}

The evaporation and condensation heat transfer coefficients $\left(h_{e}\right.$ and $\left.h_{c}\right)$ were calculated from the 


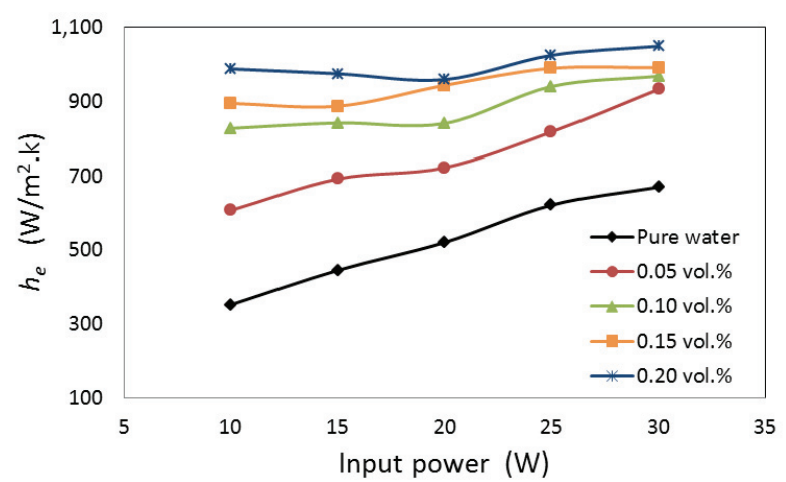

(a) Evaporation heat transfer coefficient

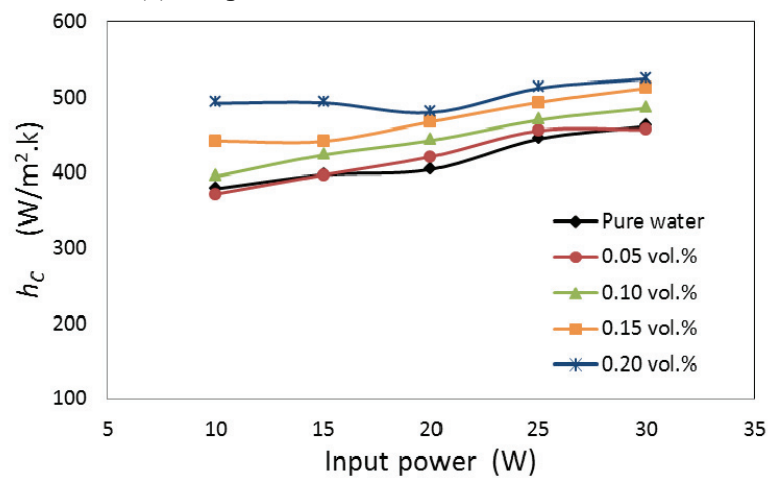

(b) Condensation heat transfer coefficient

Fig. 8 Effect of input power and concentration on the heat transfer coefficient of each test section.

temperature distributions using the following Eqs. (3) and (4):

$$
\begin{gathered}
h_{e}=\frac{Q_{i n}}{A_{e}\left(T_{H}-T_{V}\right)} \\
h_{C}=\frac{Q_{i n}}{A_{C}\left(T_{V}-T_{C}\right)}
\end{gathered}
$$

where, $T_{v}$ is the vapor temperature which could be measured from the surface of the adiabatic section, $A_{e}$ is the cross section area of the evaporator section and $A_{C}$ is the cross section area of the condenser section.

Fig. 8 represents the evaporation and condensation heat transfer coefficient respect to heat load for all the working fluids. It is observed that muti-heat pipe charged with $\mathrm{GO} /$ water nanofluid showed high heat transfer coefficients compared with that of the pure water heat pipe. Also, the evaporation and condensation heat transfer coefficient significantly improved with increasing the input power. The evaporator heat transfer coefficient increases with increasing volume concentration for the same heat load. The highest heat transfer coefficient is obtained at the volume fraction of $0.2 \%$. The nanofluids can enhance the heat transfer with different reasons: the addition of nanoparticles to base fluid changes the heat transfer mechanism so that the thermal conductivity increases the Brownian motion, dispersion, and fluctuation of the nanoparticles near the wall which leads to an increase in the energy exchange rates [16].

\section{Conclusions}

An experimental study was performed to investigate the thermal performance of multi-heat pipe using graphene oxide/water nanofluid. Graphene oxide was synthesized by modified Hummers method. The following conclusions are deduced from this study:

(1) The heat transfer performance of this multi-heat pipe is enhanced by suspension of nanoparticles in comparison with that of base fluid (pure water).

(2) The wall temperature of the evaporator and condenser increased by rise in the input heat load. With increasing concentrations, the wall temperature of the evaporator decreased and the wall temperature of the condenser increased. Adding GO nanoparticles to the base fluid is the main reason to decrease the mean temperature of the evaporator section.

(3) Thermal resistance values of the $\mathrm{GO} /$ water nanofluids-filled heat pipes were lower than those of the water heat pipe.

(4) The evaporation and condensation heat transfer coefficient were improved by increasing the input power and nanofluid volume concentration.

\section{Acknowledgements}

The first author would like to acknowledge the Cultural Affairs and Missions Sector, Ministry of Higher education, Egypt, for providing the financial support (Ph.D. scholarship) for this research and the extended help of Thermal Engineering Laboratory under the Department of Mechanical System 
Engineering, Kumamoto University, Japan, for providing the facility for experimentation.

\section{References}

[1] Kole, M., and Dey, T. K. 2013. "Thermal Performance of Screen Mesh Wick Heat Pipes Using Water-Based Copper Nanofluids." Applied Thermal Engineering 50 (1): 763-70.

[2] Lazarus, G. A., Wongwises, S., and Babu, J. 2015. "Heat Transfer Performance of a Glass Thermosyphon Using Graphene-Acetone Nanofluid." Journal of Heat Transfer 137 (11): 111502/1-9.

[3] Azizi, M., Hosseini, M., Zafarnak, S., Shanbedi, M., and Amiri, A. 2013. "Experimental Analysis of Thermal Performance in a Two-Phase Closed Thermosiphon Using Graphene/Water Nanofluid." Industrial \& Engineering Chemistry Research 52 (29): 10015-21.

[4] Kim, K. M., and Bang, I. C. 2015. "Effects of Graphene Oxide Nanofluids on Heat Pipe Performance and Capillary Limits." International Journal of Thermal Sciences 100 (10): 346-56.

[5] Noie, S. H., Heris, S. Z., Kahani, M., and Nowee, S. M. 2009. "Heat Transfer Enhancement Using $\mathrm{Al}_{2} \mathrm{O}_{3}$ /Water Nanofluid in a Two-Phase Closed Thermosyphon." International Journal of Heat and Fluid Flow 30 (4): 700-5.

[6] Guo, W., and Nutter, D. W. 2009. "An Experimental Study of Axial Conduction through a Thermosyphon Pipe Wall." Applied Thermal Engineering 29 (17): 3536-41.

[7] Ghanbarpour, M., Nikkam, N., Khodabanndeh, R., and Toprak, M. 2013. "Experimental Study of Nanofluid Effect on the Thermal Performance of Screen Mesh Heat Pipe." In Proceedings of 13th UK Heat Transfer Conference, 98/1-8.

[8] Menlik, T., Sozen, A., Gürü, M., and Oztas, S. 2015. "Heat Transfer Enhancement Using Mgo/Water Nanofluid in
Heat Pipe." Journal of the Energy Institute 88 (10): 247-57.

[9] Goshayeshi, H. R., Goodarzi, M., Safaei, M. R., and Dahari, M. 2016. "Experimental Study on the Effect of Inclination Angle on Heat Transfer Enhancement of a Ferrofluid in a Closed Loop Oscillating Heat Pipe under Magnetic Field." Experimental Thermal and Fluid Science 74 (1): 265-70.

[10] Noie, S. H. 2014. "Heat Transfer Characteristics of a Two-Phase Closed Thermosyphon." Applied Thermal Engineering 25 (4): 495-506.

[11] Karthikeyan, V. K., Ramachandran, K., Pillai, B. C., and Solomon, A. B. 2014. "Effect of Nanofluids on Thermal Performance of Closed Loop Pulsating Heat Pipe." Experimental Thermal and Fluid Science 54 (April): 171-8.

[12] Wannapakhe, S., Rittidech, S., Bubphachot, B., and Watanabe, O. 2009. "Heat Transfer Rate of a Closed-Loop Oscillating Heat Pipe with Check Valves Using Silver Nanofluid as Working Fluid." Journal of Mechanical Science and Technology 23 (6): 1576-82.

[13] Yulong, J., Hongbin, M., Fengmin, S., and Wanga, G. 2011. "Particle Size Effect on Heat Transfer Performance in an Oscillating Heat Pipe." Experimental Thermal and Fluid Science 35 (4): 724-7.

[14] Salem, M., Meakhail, T., Bassily, M., and Torii, S. 2016. "Turbulent Convective Heat Transfer of Graphene Oxide Nanofluid through Horizontal Tube." International Journal of Engineering Sciences \& Research Technology 5 (2): 898-906.

[15] Hummers, W., and Offeman, R. E. 1958. "Preparation of Graphitic Oxide." Journal of the American Chemical Society 80 (6): 1339.

[16] Heris, S. Z., Nassan, T. H., and Noie, S. 2011. "CuO/Water Nanofluid Convective Heat Transfer through Square Duct under Uniform Heat Flux." International Journal of Nanoscience and Nanotechnology 7 (3): 111-20. 